\title{
The use of SCORM in a community based Learning Management System
}

\author{
Luigi Colazzo, Andrea Molinari and Nicola Villa \\ University of Trento, Department of Computer and Management Sciences - Laboratory of \\ Maieutics \\ Trento, Italy
}

\section{Introduction}

The paper illustrates our experience as designers, developers, experimenters and administrators of a virtual communities system (VCS) used by the Faculty of Economics of our University. The idea to equip the faculty with such a platform goes back to the end of the $90 \mathrm{~s}$ and the platform itself has in the meantime undergone at least total and several partial restructuring processes, starting from being an e-learning system and evolving into the idea of managing and supporting virtual communities. In the years that followed, considerations based on our double role of administrators of a real service and developers of software have convinced us of the need for a radical change of the platform. The main reasons for this decision can be summed up as follows:

An e-Learning system used in a real teaching context cannot act as an isolated system but must be considered as one of the components of the whole information system of a teaching institution (Colazzo \& Molinari, 2002).

The metaphor of 'course' used in that first creation was adequate for covering the needs of communication and cooperation that take place in the daily work of a teaching institute.

The daily interaction of subjects within the community of people that gravitates around a course needs to have a higher level of flexibility in defining roles, rights, duties, permissions, etc. within the environment of that same "community".

Following this conviction the system has been completely rewritten and the new version is at present in use at our university as a technological platform for projects of blended learning at our and other faculties. The system is called On Line Communities and will briefly be described under point one of this paper. Recently On Line Communities has been adopted as a model by the Autonomous Province of Trento (Italy) for developing their own technological platform for Life-Long Learning (LLL) projects. As a consequence, we are at present rewriting the software in order to adapt it to the requirements of our customer. On Line Communities is a multi-standard system, that is to say a system purposefully neutral compared to the nature of objects in use. There are various reasons for this decision taken many years ago and which has proved itself most productive. To sum it up: 
A Learning Object (LO) by definition can be a very simple or complicated object, from a text to a very complex software: to put a constraint on LOs accessible through the VCS does not seem to be indicated.

A VCS aimed at university teaching has a high variability in the nature and format of the LO, for example, an LO containing a textual demonstration of a theorem will almost certainly be written in Latex, while the text "De bello gallico" could be made accessible in Html rather than in PDF file.

University lecturers like to change their courses from one year to the next and often prefer to use their own LO rather that those available on the market or on the web. Furthermore, a lecturer would hardly use the LO of another lecturer unless s/he wanted to make a point. This, therefore, eliminates the need for a Repository and also a great deal of the meta-data.

Basically, On Line Communities considers LO to be any kind of electronic document that can be used / exchanged through the net: from a text to a hardware. This choice will remain substantially unvaried but among the requirements of the new application, that aim at training courses of the Trentino provincial administration, there is the need to consent the use of didactic material consistent with the Shareable Content Object Reference Model (SCORM) standard of ADL (Advanced Distribuited Learning, 2004). The authors of the SCORM-compliant material have to respect the specifications of re-usability, duration, portability, inter-operational function and accessibility. The specifications of the structure of the didactic material of a SCORM package is based on the use of meta-data through which it is possible to represent: a) the navigation method and the sequencing in the structure; $b$ ) the meta-data of the learning objects (LOM) of a specific course, that is the aggregation model (CAM). The LOM are not very effective in as much as their aim is that of defining a conceptual scheme for the representation of the internal structure of a learning object, but they do not define the contents of a learning object itself.

The representation of the learning objects covers an aspect of primary importance, especially if these are interactive (Díaz et al., 2007). One of the requirements imposed by the need of our customers is indeed that of allowing the use of didactic material consistent with the SCORM standard; a method which, as we shall see, differs from our own approach. This is how the motivation emerges to study solutions compatible with our platform, in such a way as to maintain it independent. The work is organized in the following way: in section one we will suggest a more detailed vision of our e-learning system, called On Line Communities, introducing also the new life-long learning project called L3. In section two we will describe the approach used to integrate into our system packages of SCORM type and the problems that a standard can create within a pre-existing e-learning applicative. In particular we want to concentrate on the enclosure of the standard to training experiences different from those initially foreseen by its authors, such as for example the use of interactive didactic forms on behalf of the course teacher. Finally, in part three, we will tackle a most delicate question that concerns the accessibility of didactic material adhering to the standard. As we shall see, in fact, this latter is a delicate point in the architecture of most SCORM-compliant tools that are in contrast with, for instance, Italian law.

\section{E-learning and Lifelong learning: On Line Communities}

In this section we will recap the characteristics of Comunità On Line portal (OnLine Communities - COMOL) (Colazzo et al., 2007), the VCS used in an example for our 
argumentation. The project started in 1998 under the name Corsi On Line (Online Courses) and in 2002 it evolved from a traditional e-learning system to a new platform based on the metaphor of virtual learning communities. On Line Courses was a system based on the initial idea of Course: all its functionalities were contained in the services within every course. The active services were divided in:

- Synchronous communication systems (chat, remote application control, videoconference);

- Asynchronous communication systems (course management, forum, mail group);

- Presentation systems (information about the lecturer, the program and the organization of the courses and the exams, timetables, books, course syllabus);

- Upload/download services (for the learning objects and the connected documents).

The project continued its activity up to the academic year 2005/2006, with 670 active courses, 17.000 users and 1.300.000 total accesses. In the final part, the project has supported the transition to the new On Line Communities project, started in 2002 with a total reengineering process of the system. The object of the new On Line Communities was to create a space in the web, where it could be possible to widen the universe of relations between the actors of the didactic processes. The core of the application is composed of some abstract entities, Virtual Communities, People (Students, Professors, Administrative Staff) and Communication Services. In detail, a virtual community is a space on the web dedicated to a collaboration objective, populated by people who communicate among each other, using a series of communication systems. These are general instruments that allow to maintain the relationship between people.

The portal is able to include one community into another, or to aggregate the communities into a transversal super-community. With these types of mechanisms it could be possible to model many types of collaborative structures, even of a high complexity. For example, hierarchical structures like Faculties, Didactic Paths, Courses, Work Groups related to a course. On Line Communities was released outside the test areas in 2005, but had been experimented since 2003. As from 2005 it was being used by the entire faculty of Economics of our University and others faculties are still experimenting the system in many types of courses. At present the system has more than 1600 active communities, 9000 users and more or less 1,500,000 real accesses since May 2009 (see Figure 1).

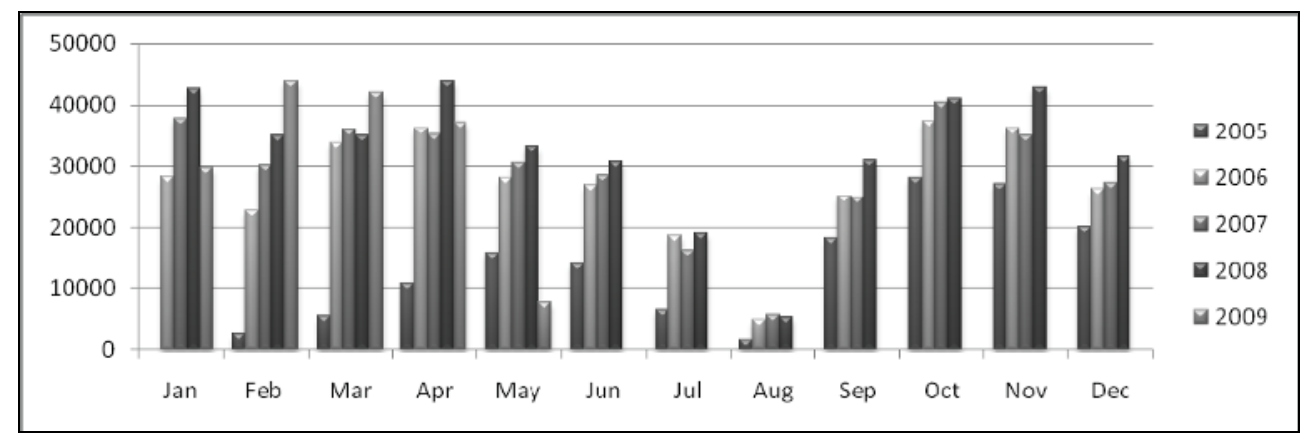

Fig. 1. On Line Communities accesses [8 $8^{\text {th }}$ May 2009]

L3 (LifeLong Learning) is a project to be implemented by our university, commissioned by 
the Autonomous Province of Trento (PAT) as a collaboration platform aimed at becoming a technological environment for training projects within the PAT itself and connected entities. In the specific case our intervention has a special valence in as far as it supports the starting up and the fruition of an e-procurement at the service of all the Public Administration of the Trentino Province. The aim of our work is mainly technological. That is to say that our task is to supply the Autonomous Province of Trento with an instrument enabling it to implement internal training processes. The system we are developing has, however, two specific characteristics:

- The system will operate on a territorial basis characterised by solid co-operation among citizens.

- The system should be able to guarantee temporal continuity of the training experience which goes beyond the single case of training and ideally will extended to many years.

These circumstances and previous experiences in creating e-learning platforms within the university have induced us to use as a basic metaphor for our system that of "virtual learning community". At the same time, however, this context of application has brought up a number of questions, crucial in a life-long learning environment. Indeed, while in an academic institution the learning communities for the bigger part coincide with the training experience (one course, one study line, etc.) in the case of life-long learning the communities are more permanent. In a certain sense they pre-exist virtual communities and survive the training experience itself.

One of the limitations of the system that the provincial body has imposed, concerns the possibility to use within its structure material consistent with the SCORM/AICC standard. Such requirement necessitates the re-planning of some of the services of the original system for the university, since the metaphor of community contrasts with that of a traditional course contained within the SCORM packages.

\section{Integrating SCORM into a virtual community system}

The integration of the SCORM standard is an element of primary importance in many of the projects in the field of e-learning. The integration within our system of the functionality and the advantages offered by the standard requires major focus on the definition of which method should be adopted so that the standard adapts itself to the metaphor of the virtual learning communities. The functional integration of the world of SCORM into an VCS concerns mainly four different functional areas:

- Tools for Authoring of SCORM compliant material;

- Up-Load of SCORM compliant material into the VCS,

- Download of SCORM material through the platform (SCORM packages and single SCO or ASSET)

- $\quad$ fruition of the SCORM material directly from within the VCS.

From a practical point of view we have identified three types of possible approaches to make our VCS compatible with the standard (Buendia Garcia \& Hervas Jorge, 2006), that obviously require different efforts. A first level of adaptation (figure 2) allows the up- and download of the entire SCORM package, to display its structure and download the single resources (Asset o SCO) contained within it. This approach seems easy to be created and, furthermore, it offers minimal functionalities to users compared to the real complexity and potentiality of the standard. 


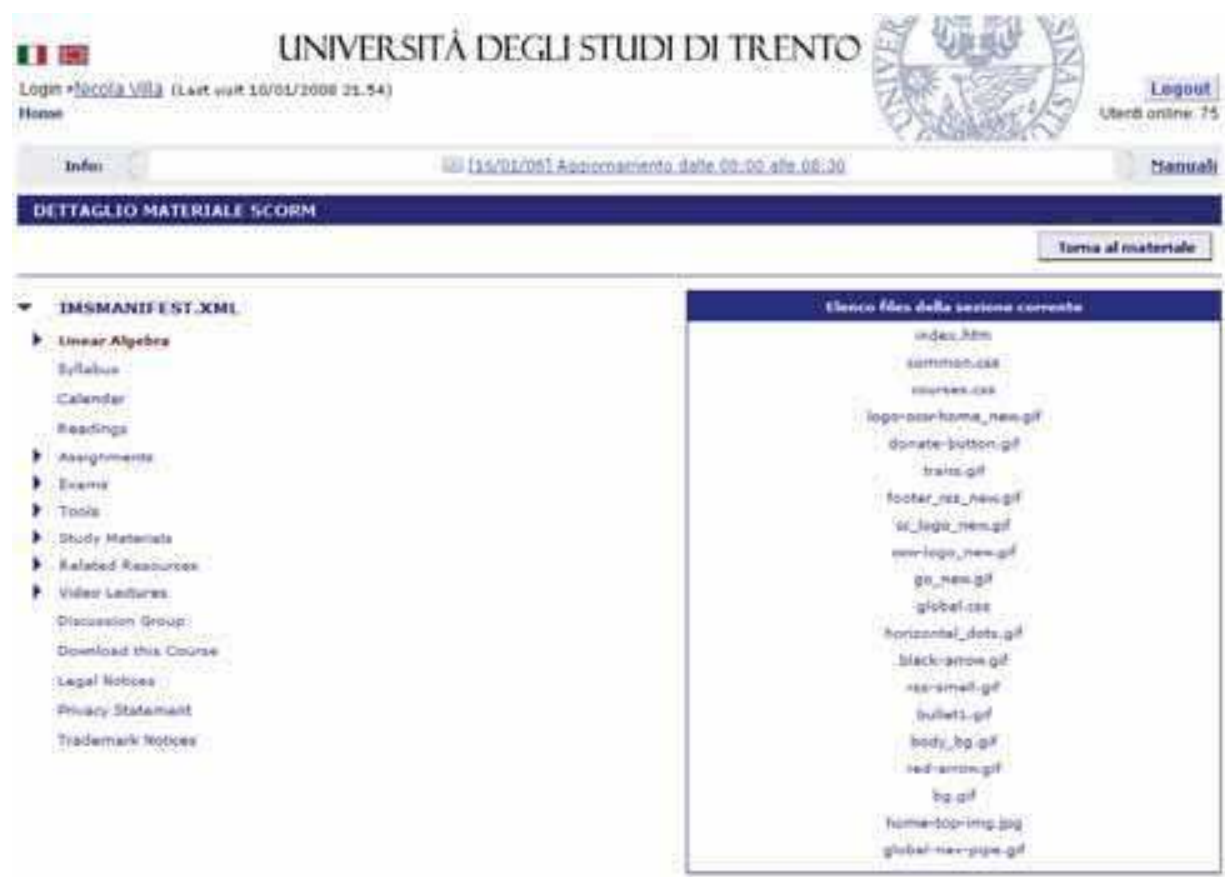

Fig. 2. Structure and contents of a SCORM package as presented in On Line Communities

One relevant problem indeed, especially for a traditional LMS with high user loads as our On Line Communities, concerns not so much the access and creation of a tree-view of the material, as the decompression of the contained material in case of download of chunks of the material itself. Indeed, for the first function the SCORM package contains an XML file that represents its content in a hierarchical form. The real problem is an architectural one: the SCORM package that represents the course (or the module, or lesson) especially with videos or html pages, can contain high numbers of files and can be of noteworthy dimensions. Having to compress them in order to permit partial download, problems of architectural choices occur:

- to load a SCORM package and then during the download phase carry out the "ondemand" decompression for the index file (IMSMANIFEST.XML) and for the various components of the package

- as above, but with immediate decompression after the upload of the index file, in such a way as to facilitate the browsing phase of the same to seek the desired chunk

- to load a SCORM package and at the same time carry out the decompression in a second repository of the whole SCORM package.

The advantages and disadvantages of the various alternatives are quite clear: within On Line Communities the third hypothesis has been chosen in function of the high work load and the users present in the system. The adopted solution sees as main drawback the doubling (at the least) of the storage occupation which, however, enables to avoid having to decompress "on the fly" upon request by the user very heavy SCORM packages, perhaps for several users at the same time. We have observed, for example, that when the teaches 
sends a note of availability of new didactic material, especially during the period of lessons, On Line Communities has a clash of accesses and requests for downloading material within few minutes. It is clear that, further to not being able to avoid these peaks, finding the SCORM package both in its hierarchic form and in its already available component, makes the task easier.

The second level of more complex implementation concerns the development of a player of SCORM that enables the execution within the system of SCORM courses (Bamidis et al., 2007), that is the guided navigation through the lessons of a course, the carrying out of a test, the taking up of the same at a later moment, etc. The implementation of an internal player presents two critical aspect:

- storing the current state of the fruition and, therefore, memorizing the various states in which the SCORM module can be used. In the case of off-line player, meaning not connected to the platform, everything is much simpler. In case of a platform of the size and user number like ours, and in particular in view of its heavy interactive use and in real time on behalf particularly of students, this solution appears to be architecturally complex.

- the flexibility on the player within the platform and/or the client: indeed, within the SCORM package we can find potentially anything and, from what we have observed in our experiments, the knowledge of and the adherence to the SCORM standard of various authoring software is decidedly to be improved upon. Naturally, if the user does not succeed in using the package because of a non adherence to the standard, the fault inevitably and undeservedly goes to the platform and not to the creator of the LO.

It must, however, be added that this hypothesis has a decidedly appealing aspect, concerning the management of bandwidth usage: in this case, from our early experiments, the direct fruition appears to be a more attractive solution than the download on one's own PC of a SCORM package in order to use it "off-line", because the waiting time and the fruition might consent a decidedly better load-balancing of net and platform resources than (perhaps at the same time) downloading of the whole package.

The last and final integration level identified contemplates the creation of an authoring system (Celentano \& Bochicchio, 2006) so that in future authors can create complete and certified SCORM packages in a guided way (Parmar et al., 2007).

This option appears for now to be of low priority for a series of reasons both technical and tactical:

- Further to customizing opensource software for our platform, this operation is certainly not painless

- Sophisticated SCORM authoring environment already exist outside our platform and so there is the risk of "reinventing the wheel"

- We are, above all, not convinced that people who create didactic material are ready to abandon their own authoring environment in order to learn a new one, especially with a conceptual meta-structure (SCORM standard) which, however hidden in the software of SCORM authoring, makes the workload heavier. We well know, also from personal experience, that who is used to creating didactic material with PowerPoint ${ }^{\mathrm{TM}}$ is unlikely to change opinion and who produces didactic material with Latex ${ }^{\mathrm{TM}}$ will have difficulty in changing such a powerful and flexible environment which had taken him/her so long to learn.

Our choice has been to proceed in a first phase leaving the tutors the possibility to publish materials created outside On Line Communities, and other users the navigation within 
them. It seemed to us an interesting solution to integrate the use of SCORM packages into the download service of didactic material of a course in that specific service. The motivation that determined this choice was dictated by the wish to maintain the user service of didactic material "transparent" compared to the format of the materials themselves. Thinking, for instance, of the notes of a lecture taken with a normal word processing software, in such a case there is no service called "textual material" because it is contained within the download of the didactic material (figure 4). In the same way, a lesson too, created previously through SCORM standard, can be downloaded from the material section just like the notes of the lessons (figure 3 ).

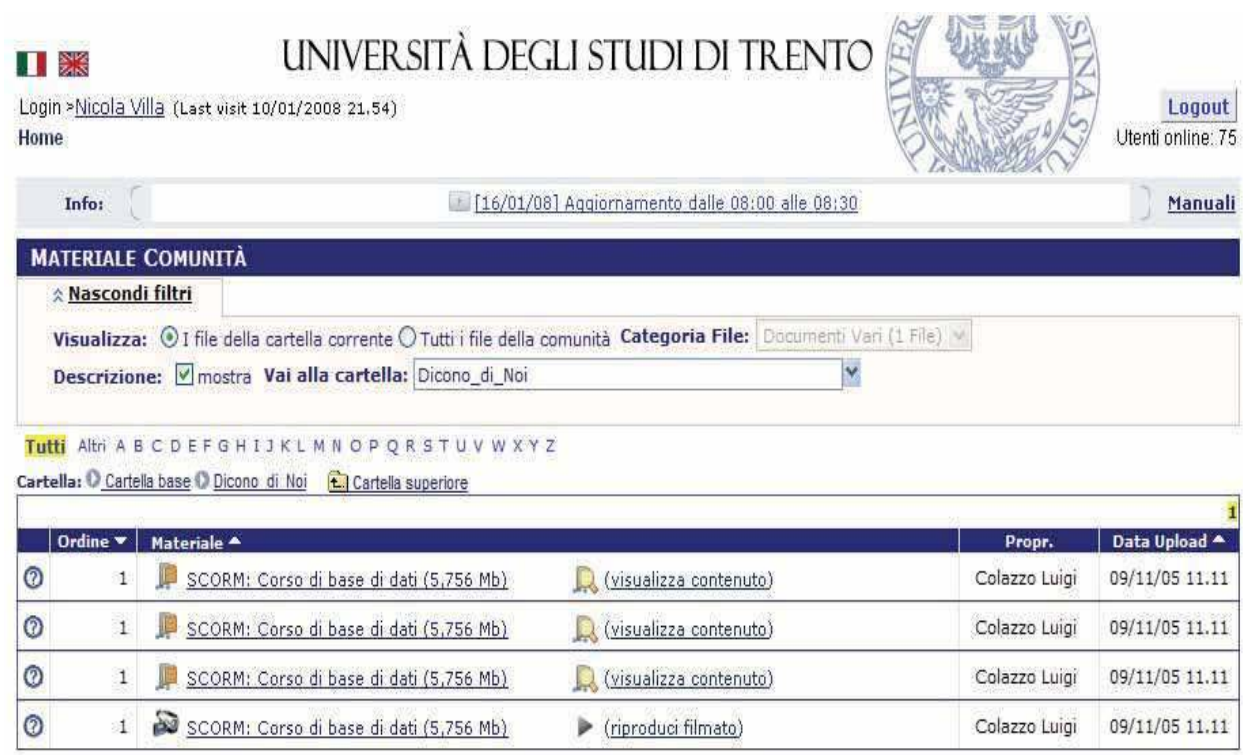

Fig. 3. Material service that also integrates the download of SCORM packages

Among the functionalities to create, there is the fruition of SCORM courses; this is possible through a nesting structure of the frame, since a SCORM course is basically composed of a set of pages that have to be reproduced "as they are". The interaction as far as navigation and evaluation of user input is concerned, will take place through the appeal of the primitives defined by ADL, inserted into the SCO, that is, the fundamental resources of the SCORM package. The structure, and even its tree representation, is however in contrast with the guidelines of accessibility that we adopt, as will be described in section three, in as much as problems are introduced both from a point of view of accessibility as well as incompatibility with some browsers.

Even the aspect concerning authoring of SCORM packages is of no simple implementation: the obligations defined in the Content Aggregation Model (CAM) of the third version of SCORM 2004, in the IEEE specifications upon which it is based (IEEE 1484.12.1) (IEEE, 2002) and in the application profile of CNIPA (Italian National Center for the Computer Science in the Public Administration) indicate the possibility to take into consideration a sub-total of meta-data in order to simplify the creation of compatible courses. This may enable us to 
create a service less invasive than it might be, so that the authors of the system may be helped in writing lessons.

One open question that we have been asking ourselves concerns the applicability of a web 2.0 approaches to the definition of SCORM didactic contents. This is an important question since the solutions adopted in the web are those in which the author is no longer classifiable with informatics; on the contrary, each web user - according to this approach - can be author of contents. In this context, collaborative and interactive applications, within which users are free to publish information on whatever topic, have become more and more popular. Part of this category can be considered services like wiki (Leuf \& Cunningham, 2001) or blog (Kline \& Burstein, 2005) that offer collaborative environments in which users can exchange information. Even On Line Communities and its evolutions in the projects of life-long learning for training courses of employees of the provincial administration, integrates services of this type but with the important addition of combining these services with the concept and architecture of "community" that, as we have seen, completely conditions and warps any e-learning service. Each user can create within the system a personal blog in which to interact with his/her colleagues establishing a social network on a community level in the widest sense, from the secretariats to courses, from recreational to research groups. This kind of collaborative and cooperative approach in which all members of the community can take part to reach a final aim, unhinges the classical concept of static lesson in which only the teacher could generate knowledge. In this case all users who take part in the learning process are able to help each other (taking part in forum, chat, wiki, etc.) improving social relations that are being established in order to favor learning.

In such ideal context of web 2.0, we unfortunately notice how the use of SCORM type packages could be a critical element, because it is not suitable to this type of solution. A lesson created according to standard is in fact static, consisting only of the information that the author had decided to offer to those following the course, the list of the lessons (even if up-datable at a later date by the author) will be adopted by the student in "as is" mode, without the possibility for interaction with the contents. This creates a relevant limitation because it transforms what could be an interactive path into a "cul-de-sac" where only the teacher controls the learning modality of the student. The possibility to include, always on behalf of the author, interactive contents within the lessons (for example, Flash ${ }^{\mathrm{TM}}$ videos of objects that can help users to understand concepts) is not excluded but it is in function of what the teacher decides to insert and not of what the user would really like.

For this reason our choice has been to integrate SCORM into our system, yet avoiding to link On Line Communities indissolubly to the standard; this is a decision we have been following up ever since the birth of the system in such a was a to make it "transparent". Hence, the integration into the system does not mean the complete adoption of the standard but rather to offer users the possibility to use their own material quite freely.

\section{Accessibility of SCORM tools and packages}

Among the various characteristics of an e-learning application aimed at studying and working population there is certainly the accessibility of the system for disabled people. The difficulty to access the contents within the SCORM packages is a question not widely dealt with so far but certainly of primary importance, given its diffusion (hoped for) and the enormous potential that it contains. We would like to introduce the topic of accessibility of 
SCORM-compliant materials, that is, the whole range of solutions and strategies suitable to make web information usable also by both physically or mentally disabled people. Part of this category are all those problems that a disabled person can meet when s/he accesses and uses information in web pages incompatible with assistive tools, because of an interface developed without the simplest usability principles. In our opinion, there is another serious problem regarding the accessibility of SCORM material: most of the statements we found in literature, citing the words "accessibility" and "SCORM", are intended in a totally different way from what they mean to unpaired people, with a general sense like "accessibility means more people can access to electronic materials". Unfortunately, the term "accessibility" is used in SCORM documentation as "The ability to locate learning content in multiple locations and to deliver it to multiple locations." Accessibility to unpaired persons is not addressed in the SCORM specifications (Craddock, 2003 ).

Up to now various international as well as national directives have been issued on the subject; we have already mentioned this question in other works, underlining for instance the incompatibility between national law (in Italy, for instance, law of 9th January 2004 (Italian Parliament, 2004) and local norms concerning the territory in which our research group is active. Having amply treated this topic in a previous work, here we just want to remind of the guidelines issued by WAI (internal organism of W3C), called Web Content Accessibility Guidelines in the version 1.0 issued in 1999 (Chisholm et al., 1999)and the version 2.0 (Caldwell, 2007) at present under revision.

On the basis of these guidelines, but also of the technical requirements foreseen by Italian law, we wish to concentrate on the analysis of a possible level of accessibility of courses offered according to SCORM standard; going back to what we said in the previous section, it is necessary to distinguish two different cases:

- the accessibility of the applications in order to offer courses

- the contents good and proper, codified according to meta-data indicated in the standard.

As far as the contents are concerned, created directly by the user and loaded within a SCORM package, the accessibility level does not depend on the standard employed but, rather, on the modality through which the user has created the didactic contents. We are thinking of the notes of a lesson codified through a text document, in case they are accessible in the same way, they will also be after having been imported into the package itself. In the same way, in case the created information and documents are already inaccessible because of their incompatibility with the above mentioned standard, the same will apply also for the lessons presented in the package. After all, the standard does not degrade the accessibility of the contents presented, but simply tries to offer its original state.

The question concerning the accessibility of the interface of an application for offering SCORM material is quite different; from our point of view this question is particularly important since we do not want to degrade the level of accessibility of our portal after the integration with the service for the use of SCORM packages. One of the pre-requisites of the player is the use of Javascript language; this is in clear contrast with the WAI recommendation, particularly 6.0 present in the first version of the WCAG, while the Italian legislation does not advise to use scripts in requisites 15 and 16 of the Italian law.

The interface of a SCORM package player is normally structured using a frame, separating graphically the contents of the lessons from navigation. This characteristic is in strong contrast not only with the WAI guidelines and requisite 2 of the Italian law but actually with 
the best practices followed by web developers. The use of frames indeed has been abandoned by the majority of programmers who prefer the implementation of different structures, more efficient and also more accessible. This is why the choice of CNIPA, an Italian public body, in setting up the regulations for the development of e-learning sites allows the use of SCORM player based on frames, appears strange to us. The directive for elearning specifically affirms that "the use of frame is allowed only in e-learning platforms that rely on SCORM is allowed, and exclusively for including the imported contents and for tracing activity" (CNIPA, 2007).This choice is probably dictated by the need to make already developed elearning applicative like ours, compatible with material previously created according to standard.

For these reasons our work group is oriented towards the development of a different solution that will guarantee the accessibility of the importation and visualization of SCORM material within the Online Community. The necessity to guarantee the use of SCORM learning objects from our e-learning portal can be a risk factor concerning the general accessibility of the system, which is configured as a fundamental requirement. The intermediary solution that has been adopted, that is, the visualization of the contents presented in LO SCORM and the possibility to download material contained it (text documents, html, images, etc.) has been thought to be completely fully accessible. In contrast with the classical tools available, we do indeed not use a frame for the implementation of this service. The list of lessons appears through javascript language but it has been implemented by a mechanism so as to be usable also in case fruition through a browser that does not support the language. As already mentioned, the user will be able to access the various contents present in the documents, but for obvious reasons we cannot guarantee the full accessibility of the downloadable material. Indeed, we are not able to control the conformity of the standard of the contents of the single files created and loaded in the packages on behalf of the users; classical examples are HTML pages, created autonomously outside our portal, that risk to be inaccessible if the author does not respect the various requirements.

\section{Conclusion}

This paper presents a necessarily synthetic view of the problem created, within already existing e-learning platforms, of two very important topics for such systems and in general for didactics assisted by ICTs, that is, the use of SCORM standard with its architectural implications on the platform itself, and the problems created by these adoptions in terms of accessibility. We have presented the solutions applied to these questions within our On Line Communities platform, in which the basic philosophy of the platform, that is to say, the idea of virtual community, offers advantages of implementation and possibility for superior development in contrast with the closure created by the simple concept of "course" as a container of SCORM material. The solution we have described in this section reflects this philosophy; we have not created SCORM-compatible communities but we have foreseen the possibility to create, insert and visualize lessons of this time within the space we are offering our users. The aspect of accessibility of SCORM material is, however, a complex problem, especially because of some incongruences in the finality of the standard, in its formulation and its legislative aspects, that make its implementation obligatory. A solution to these questions or, even possible structural intervention on the standard, on the technologies 
available to diversely able people and on the legislation would be most welcome.

\section{References}

Advanced Distribuited Learning (2004). SCORM 2004 3rd edition - Content Aggregation Model, retrieved from http://www.adlnet.gov/downloads/AuthNotReqd.aspx?FileName $=$ SCORM.2004.3ED.DocSuite.zip\&ID=237

Bamidis, Panagiotis D.; Nikolaidou, Maria M.; Konstantinidis, Stathis Th. \& Pappas, Costas (2007). A Proposed Framework for Accreditation of Online Continuing Medical Education, Computer-Based Medical Systems, 2007. CBMS apos;07. Twentieth IEEE International Symposium on Volume, Issue , 20-22 June 2007 Page(s):693 - 700

Buendia Garcia, F. \& Hervas Jorge, A. (2006). Evaluating e-learning platforms through SCORM specifications. In: Proceedings of IADIS Virtual Multi Conference on Computer Science and Information Systems (MCCSIS 2006) (15 - 19 May 2006). www.iadis. org/Multi2006/Papers/15/S020_EL.pdf

Caldwell, B.; Cooper, M.; Guarino Reid, L. \& Vanderheiden, G. (2007). Web Content Accessibility Guidelines 2.0, W3C working draft

Celentano, M. \& Bochicchio, M. (2006). A Real-Time Authoring Tools For Scorm-Compliant Learning Objects. In E. Pearson \& P. Bohman (Eds.), Proceedings of World Conference on Educational Multimedia, Hypermedia and Telecommunications 2006 (pp. 2061-2068). Chesapeake, VA: AACE.

Chisholm, W.; Venderheiden, G. \& Jacobs I. (1999). Web Content Accessibility Guidelines 1.0, W3C Recommendation

CNIPA (2007). Vademecum per la realizzazione di progetti formativi in modalità e-learning nelle pubbliche amministrazioni, second edition. In: I Quaderni n. 32, april 2007, Rome

Colazzo, L. \& Molinari A. (2002). From Learning Management Systems To Learning Information Systems: One Possible Evolution Of E-Learning. In: Proc. Communications, Internet and Information Technology (CIIT) Conference, St. Thomas, USA - November 1820, 2002

Colazzo, L.; Haller, H. \& Molinari A. (2007). WAYS - What Are You Studying? A community tool for learners on the move. In: Proc. of ED-MEDIA 2007, edit by Craig Montgomerie \& Jane Seale,June 25- June 29, 2007; Vancouver BC, Canada

Craddock, G. (2003), Assistive Technology - Shaping the Future, ISBN 1586033735, IOS Press

Díaz, F.; Osorio, M.; Amadeo, A. \& Schiavoni, A. (2006). Standardizing Educative Content with SCORM: A Case Study. In C. Crawford et al. (Eds.), Proceedings of Society for Information Technology and Teacher Education International Conference 2006 (pp. 318-323). Chesapeake, VA: AACE.

IEEE (2002) Draft Standard for Learning Object Metadata - IEEE 1484.12.1. Retrieved from http://ltsc.ieee.org/wg12/files/LOM_1484_12_1_v1_Final_Draft.pdf.

Italian Parliament (2004). Disposizioni per favorire l'accesso dei soggetti disabili agli strumenti informatici, Legge 9 gennaio 2004, n. 4

Kline D. \& Burstein D. (2005). Blog!: How the Newest Media Revolution is Changing Politics. In: Business, and Culture, Squibnocket Partners, L.L.C.

Leuf B. \& Cunningham W. (2001). The Wiki way: quick collaboration on the Web. In: AddisonWesley Longman Publishing Co., Inc. Boston, MA, USA 
Parmar, K.; Anane, R.; Hendley, R. J. (2007). Architecture of a SCORM-Compliant Assessment Authoring Tool, 2007. ICCSA 2007. International Conference on Computational Science and its Applications, 26-29 Aug. 2007 Kuala Lampur, Malaysia, Page(s):110 $-117$ 


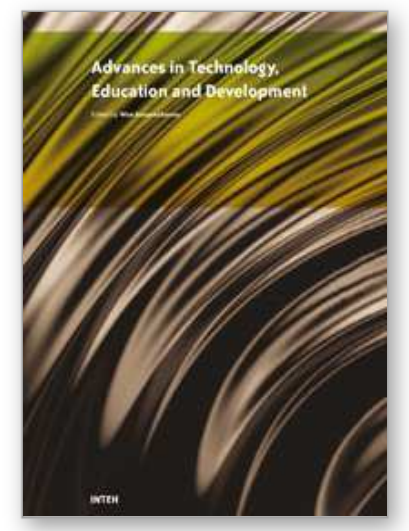

\section{Advances in Technology, Education and Development \\ Edited by Wim Kouwenhoven}

ISBN 978-953-307-011-7

Hard cover, 474 pages

Publisher InTech

Published online 01, October, 2009

Published in print edition October, 2009

From 3rd to 5th March 2008 the International Association of Technology, Education and Development organised its International Technology, Education and Development Conference in Valencia, Spain. Over a hundred papers were presented by participants from a great variety of countries. Summarising, this book provides a kaleidoscopic view of work that is done, all over the world in (higher) education, characterised by the key words 'Education" and 'Development'. I wish the reader an enlightening experience.

\section{How to reference}

In order to correctly reference this scholarly work, feel free to copy and paste the following:

Luigi Colazzo, Andrea Molinari and Nicola Villa (2009). The Use of SCORM in a Community Based Learning Management System, Advances in Technology, Education and Development, Wim Kouwenhoven (Ed.), ISBN: 978-953-307-011-7, InTech, Available from: http://www.intechopen.com/books/advances-in-technologyeducation-and-development/the-use-of-scorm-in-a-community-based-learning-management-system

\section{INTECH}

open science | open minds

\section{InTech Europe}

University Campus STeP Ri Slavka Krautzeka 83/A 51000 Rijeka, Croatia Phone: +385 (51) 770447

Fax: +385 (51) 686166 www.intechopen.com

\section{InTech China}

Unit 405, Office Block, Hotel Equatorial Shanghai No.65, Yan An Road (West), Shanghai, 200040, China 中国上海市延安西路65号上海国际贵都大饭店办公楼405单元

Phone: +86-21-62489820

Fax: +86-21-62489821 
(C) 2009 The Author(s). Licensee IntechOpen. This chapter is distributed under the terms of the Creative Commons Attribution-NonCommercial-ShareAlike-3.0 License, which permits use, distribution and reproduction for non-commercial purposes, provided the original is properly cited and derivative works building on this content are distributed under the same license. 